EASTERN EUROPEAN JOURNAL OF TRANSNATIONAL RELATIONS

2018 Vol. 2 No. 2

DOI: 10.15290/eejtr.2018.02.02.03

Uladzislau Beizerau ${ }^{1}$

Francisk Skorina Gomel State University, Faculty of Psychology and Pedagogics

\title{
Integration Processes and Trends in the World Educational Space: The Case of CIS Countries
}

\begin{abstract}
Summary. The article focuses on the processes taking place in the education systems of the Eastern Europe countries. The general overview of the changes in the global higher education systems is presented in the article. The world educational space today is in need of serious transformations. Much attention is paid to the description and analyses of the integration processes taking place in European higher education and education within those countries comprising the Commonwealth of Independent States. The Comparative approach and literature review are mainly used as the methodology in the article.
\end{abstract}

Keywords: integration, process of integration, educational system, degree, mobility, CIS, educational space.

\section{Introduction}

The accessibility of higher education for wide sections of the population, not just for the elite, is a pressing issue in many countries. For example, higher education in America for many years, was only available to those in the higher levels of society who could afford it. However, after World War II this began to change, culminating in the Higher Education Amendments of 1972, in which the principles of the democratic character and accessibility of higher education were formulated, and later colleges and universities were opened in each of the 50 states. Since 1972 millions

1 An Associate Professor, PhD, and a Dean of the Faculty of Psychology and Pedagogics, F. Scorina Gomel State University (Gomel, Belarus). ORCID ID: https://orcid.org/0000-00030349-1653. E-mail: v_beizerov@yahoo.com. 
of students from fairly poor families, have had the opportunity to study supported by scholarships, state grants and student loans.

In India, class or caste barriers still exist and this also prevents people from the lower classes entering higher education. The government's plan to reserve places at universities specifically for people from lower castes was subjected to great criticism and provoked protests from representatives of the highest castes. Similar events occurred earlier in Britain and in France. Although the number of students in higher education might increase every year, in the United States and Japan, where education is very expensive, most students are still representatives of the middle and upper classes. In the University of Tokyo, for example, the average annual income of parents of junior students is 82,500 USD while the average annual income in the country is 57,500 USD. Research conducted in colleges and universities of the United States has shown that only 3\% of all students are representatives of poor families (Higher Ed Inc., 2018).

The world educational space is in need of serious transformation. For many decades the education systems in Asian countries has followed the example of Europe. The Asian powers, and especially Japan, quickly realised that only the modernisation and development of education systems would lead to progress of the country as a whole. Subsequently, the flowering of education began in Eastern civilisations, and the West began to accept the positive experience of Asian states, particularly in the field of education. For example, numerous agreements on exchange programmes for students and teachers have been signed between a number of western universities and universities in China and in India. However, it is not without challenges. While education systems do influence each other, simply borrowing a copy of the European model of education for another context can be problematic. Asian faculties of natural sciences, mathematics and physics of universities and technical colleges provide training in programmes identical to those found in European and American higher education institutions. However, in the humanities, the training programme is based on benchmarks of national and religious values.

\section{Integration processes in Europe}

In European countries, a trend towards greater integration of higher education institutions can be observed. A new stage of this process began in 1998 after the signing in Paris by the ministers of education of the four leading European states (Great Britain, Germany, Italy and France) of a joint declaration aimed at eliminating barriers to the close cooperation of European countries in higher education. The declaration was open to other European countries who wished to join the single European space for higher education. In 1999 the document signed in the Italian city 
of Bologna became a logical continuation of the Paris Declaration (The history of European cooperation, 2006).

According to the joint declaration of European ministers of education, higher education on the continent should be further based on the recognition of two main steps. The first step is to provide students with access to interdisciplinary programmes, in-depth study of languages and modern information technologies, and general scientific and vocational training. Secondly, it offers two levels of education, namely, master's and doctoral studies. Continuity is established between these programmes (Bologna for pedestrians, 1999). The proposals contained in the Bologna Declaration to create a single European educational space include the following:

- A system of degrees and qualifications can be easily understood; reflection of the details in the form of an application that is easy to understand/read, Diploma Supplement;

- A multi-level education system provides for a relatively short educational trajectory, namely, a bachelor's degree (3-4 years) as the entry stage to higher education, as well as the possible continuation of training for a master's degree;

- The declaration offers a credit system, for example, the European Credit Transfer System (ECTS), to ensure student mobility and recognition of accumulative "lifelong learning" possibilities. This will require the inclusion of higher education institutions in the strategic planning of long-term education. The value of student mobility means for example, a student is supposed to study for one semester in a "foreign" university. The role of the university in organising and promoting mobility is relevant not only for students, but also for teachers;

- The participation of students as full partners in the Bologna Process is assumed, both at the university and student government levels, and at the level of education strategy discussion;

- The autonomy of higher education institutions, granting them the right to independence of their internal organisation and management, as well as the determination of the content of training and the development of modules and courses.

- The unity of the three spaces: the European Higher Education Area (EHEA), the European Research Area (ERA), and the innovative area of the ERJA for a knowledge-based society;

- The European approach to quality assurance in higher education, characterised by many indicators, includes ensuring accountability and organisation of training systems, transparency of evaluation activities and evaluation tools, mutual recognition of national quality assurance and accreditation systems 
confirming compliance and/or stimulation of improvements, strengthening the competitiveness of the European educational system.

Of the main provisions of the Bologna Process, the most significant are: mobility, quality, recognition of degrees.

\section{Changes in education within CIS countries}

Analysis of the experience of introducing the provisions of the Bologna Process in higher education institutions of the Commonwealth of Independent States (CIS) (in different countries in the early 2000s) showed a number of significant obstacles related to the features of post-Soviet education. First, it is the training trajectory fixed by the State Standard and determined from the very beginning, which is an obstacles in the implementation of student mobility. Second, there are legal problems in the area of signing contracts between institutions of higher education of various legal forms (public and private). Third, social conditions make it difficult to adapt to European requirements. Fourth, psychological barriers in the perception of bachelor and master qualifications by consumers of educational services can impede the process. Despite these obstacles, the implementation of the provisions of the Bologna Process in educational practice also has positive results.

Borrowing all new and unfamiliar foreign models, even if one of the best in the world according to the western analysts, the Soviet educational model was almost completely rejected. This circumstance distanced the former soviet federal republics from each other.

A comparative analysis of educational legislation that currently exists in the majority of CIS states allows us to draw a number of conclusions and recommendations on the preparation of the concept of a model educational code for these states which will become the basis for the reintegration of education. The structure of all laws are generally identical, there are no significant differences between them. Many sections and articles of these laws also coincide in content. Differences between them are recognised only at the specification level. In terms of content, most closely matched are the articles of the laws defining the principles of state policy in the field of education (for example, Article 2 of the Law of the Russian Federation "On Education"); the organisational structure of education systems (education levels, types of educational institutions and their curricula, management), and education financing issues. However, despite the closeness of these articles, significant discrepancies also exist. They relate to national educational standards, levels of compulsory education and openness of educational systems. Compulsory secondary (complete) general education exists only in the Republic of Kazakhstan; in other countries, basic general education ( 9 grades of schoolthe) is considered compulsory. 
Orientation to the world level of education and the international educational standards is to a certain extent proclaimed in the educational legislation of the Azerbaijan Republic, the Republic of Belarus, the Republic of Kazakhstan, the Kyrgyz Republic, the Republic of Moldova and others. The legislation of the Russian Federation states that the content of education should provide "an adequate world level of general and professional culture" (Law of Russian Federation. 10 July 1992. N 3266-1 "On Education", Federal Law on Higher Education) and higher professional education. 22 August 1996 N 125-Ф3).

The legislation of the Commonwealth countries in the field of education involves: the introduction of a multi-level system of training (bachelor, master); the creation of the private sector in the educational systems of the countries in question; the introduction of a multi-channel system of education financing, including tuition fees; the introduction of new forms of learning quality control (licensing, accreditation); the declaration of such principles as democratisation of educational systems, autonomy of educational institutions and academic freedoms, diversification of types of educational institutions and their training programmes.

At the same time, the current educational legislation of the CIS States is not focused on education systems, on their functioning within the framework of the common educational space of the CIS, as well as in the system of world educational space. International agreements such as the Universal Declaration of Human Rights impose obligations on CIS States. One example is that "primary education must be compulsory, technical and vocational education must be equally accessible to all based on the abilities of everyone" (Article 26 (1)). In addition, the following documents should be noted: the UNESCO Convention against Discrimination in Education (1960); UNESCO recommendations on the status of teaching staff of higher educational institutions (1997); Recommendations of the position of teachers (Paris, 1966); Recommendations of commissions and international conferences, in particular, the International Commission on Education in the 21st century, and finally, the World Declaration on Higher Education in the 21st Century: approaches and practical measures as well as a framework of priority actions aimed at the reform and development of higher education, World conference on higher education (9 October 1998, Paris).

Given the exceptional importance of the World Declaration, all CIS countries should make efforts with the help of UNESCO so that the relevant provisions of the Declaration are reflected in national legislation and regulations, as well as in practical activities, and become the basis for developing a generic education code for the CIS member states.

In developing basic provisions of the model educational code, it is necessary to use basic principles laid down in the Model Law on Education of the CIS member states, in particular: maintaining the independence of the educational systems of 
individual CIS member states, their national characteristics and historical traditions; focus on the adequacy and quality of education.

Integration of the educational systems of the CIS countries should occur in the implementation of the strategic goals of state policy in the field of education and addressing priorities, focusing on the preparation and implementation of structural reforms of educational systems in accordance with modern requirements (diversification, autonomy, democratisation, etc.). There should be support for evidence-based measurement methods in education and effective systems for monitoring of educational systems created on their basis in order to timely identify and eliminate of negative phenomena and trends in this area.

The tool for the development and implementation of state policy to support integration processes in the field of education is the interstate programme for the formation of unified educational space of the CIS countries, approved by authorised bodies of the CIS, ensuring its legal, organisational, financial, material, personnel, scientific methodological and informational support.

However, integration processes in the CIS are only a part of the universal processes of globalisation and integration. It can also be noted that integration in the CIS is a reintegration, or restoration of what already existed. It is no secret that the USSR functioned as a single space including in education (the education systems of all soviet republics resembled each other). With the collapse of the Soviet Union and the acquisition of independence by all republics, their education systems, while continuing to preserve the foundations of the Soviet model, underwent fundamental changes (Liferov, A., 2001).

Integration into the world space, in particular the European educational space, looks much more complicated. The Soviet education system existed for more than 70 years and is significantly different from other systems. This causes numerous problems that are currently slowing down integration processes at all levels. Indeed, much deeper transformations of all elements of the system seem necessary.

\section{Trends of integration in education}

Thus, summarising the above, we can discuss the following trends which characterise development of the integration processes involved:

- growth in education;

- diversification of education according to institutional forms, levels and content;

- cooperation of the states in the course of convergence of government policies in the field of education;

- partnership at all levels of government, including education;

- internationalisation of education; 
- educational competition;

- universality, globalisation, flexibility of education;

- access to education;

- online education;

- technologisation and computerisation of educational infrastructure;

- lifelong education;

- creation of targeted supranational programmes;

- transformation of traditional systems, etc.

There are other trends affecting the development of integration processes in education, but in the author's opinion, to address the problems of research, the above are the most significant.

The methodological aspects of the modelling of integration processes are determined by the initial conceptual foundations, the ideas of the essence, the content of the phenomenon under study, as well as the trends in the development of integration processes in the world educational space. To realise the full-scale integration of educational systems, it is necessary to take into account: the public, state, as well as the interstate nature of these processes. In addition, aspects such as the setting of priorities and the level of initiative of the interacting parties; it is necessary to consider the possibility of involving a wide range of participants from all parties in the system of integrated interaction and the involvement of research experts in the further design and development of the system of integrative communications.

Any integration is the accumulation of ideas, goals and theories around a central object, that will become the basis for creating a complete system. One of the integration mechanisms is the inclusion in the complex of all necessary elements in certain proportions, which should interact in a coordinated and orderly manner to preserve the integrity of the system without risk of its destruction. Thus, compatibility, similarities and hierarchy of the various components of the system should be subordinated to a single goal (Afanasiev, V., 1973).

Integration will be successful if one of the fundamental laws of philosophy is observed, namely the transition of quantity into quality. In other words, the creation of numerous unified educational institutions, the adoption of integrative acts will become successful only when all of them begin to function, and the system acquires new quality as a result of the development of internal system communications. Undoubtedly, in the case of the inclusion of elements in new communications, they will change, which will subsequently lead to fundamental changes in the system, changes in a number of functions of elements and, consequently, to the transformation of the system into a completely new system having new properties and qualities.

The main initial goals and objectives of integration are to ensure the integrity of ideas, a unified methodology, and priority areas of the educational process. Such goals and objectives determine the choice of integration model. Competent 
implementation of them will allow integration in a single complex and on a much wider scale at the same time.

When implementing integration processes, the systems approach should play a crucial role in related research. The new system should acquire new qualities, mainly due to the interaction of the constituent components of the system. This is because the new system cannot simply be the sum of its component parts. In its structure as a whole, where all of the components are interconnected and interact with each other; a change in one component leads to a change in all others and, as a result, ultimately to the emergence of a completely new system. With reasonable implementation of the integration tasks, new qualities and properties that have been introduced into the system should not replace existing positive properties and qualities, but should closely interact with them in accordance with the principles of coexistence of old and new. Also, with the appearance of new components in the system, the existing (and possibly well-tested) components should not disappear.

In the methodological understanding, the components of the system are those structural units, the interaction of which ensures and enables the qualitative features inherent in a system. The teacher and the student, within the framework of a complex network of professional, social and political, interpersonal and personal, and corporate affairs, are the main components of the system. The second group of components of any public system includes economic, socio-political, and cultural processes. To understand the specifics of the system of integration of educational processes, learning processes are of paramount importance. The third group of components consists of social ideas which exist in public and individual consciousness and serve to express the goals this element of the system is required to achieve and the historical period to which specific social groups of people belong. Examples of such ideas in the integration processes, are the ideas of globalisation, cosmopolitism and humanity. The fourth group of components includes material objects; institutional structures including auditoriums, laboratories and the like, as well as devices, equipment and other tutorial necessities, without which the existence of the system is impossible. Indeed, this set of components largely determines the system and its quality and, as such, the structure of the system of integration is tied to them.

The systemic-functional aspect of modelling integration processes in education is the product of input activities and the activity of system and its components, and the orientation of this activity towards obtaining a level of integrity useful for the preservation and development of system results. The functions of the components in relation to the system are of the nature of interactions, consolidations, which provide a useful result to the system. As established by Anohin, in the systemic-functional aspect, it is methodologically important to open coordination and communication links between those components of the system that provide the minimum basis of its activity and adaptation to the environment. For the system of integration of 
education, the systemic-functional aspect will be characterised by the activity of the managing director and by coordinating the centres involved (Anohin, 1980).

The implementation of the process of integration in the interaction of educational systems of different countries is ensured in the presence of such conditions as integrity of the educational process, the unity of the language environment, the involvement of participants in the educational process in all joint forms of , the combination of traditional (national and local) and world culture in the content of education, and the wide use of national educational traditions in the educational process.

Another integration option, namely direct integration into the European and world educational space, implies simultaneous integration into the universal educational space, European and Eurasian. By taking the path of multilateral integration, one can reach the optimum level by satisfying the needs of the majority of the population. Multi-vector integration into the field of education is also consistent with the foreign policy of the CIS countries.

Integration in education can be simultaneously considered as a process and as a system. Any system incorporates interconnected and interoperable components. The process involves the presence of certain actions aimed at achieving the final result. By a similar consideration of integration, it is clearly seen that its components are interconnected with procedural actions.

Integration is understood as the result of the process of unification and unity, which is a condition for the harmonious stability and orderly functioning of all parts as a whole. The relevance of integration in education was came to light in the 1990s. A distinctive feature of the research conducted in this period is a complete picture of integration of rich historiographic material, based on the use of systemic and historical methods. At the same time, the problem of integration was considered by scholars against the background of a general review of the state of education. Since the mid1990s, the problem of integration has become an independent subject of scientific analysis. Available research on the problem of integrating educational systems can be broadly divided into three categories, namely: 1) work on the characteristic and research of world education; 2) work on the characterisation and comparison of national education systems in general; and 3) work reflecting the characterisation and analysis of integration processes occurring in regional educational systems.

Integration processes occur in education under the influence of the process of globalisation and form a part of universal processes of integration in all spheres. Globalisation acts as one of the most important parameters of the existence of human society, it reflects the processes of interdependence of the various components of the world community and expresses the idea of recognising the dignity of all mankind as a sociobiological education. In the context of globalisation of world processes and cultural convergence, the education system is considered an effective mechanism of ethnocultural identification of one individual with another, as a means to harmonise interethnic relations. Through globalisation, the subjects of international relations 
have greater opportunities in their activities, there is a unification in all spheres of human activity and thus uniform international standards are engendered.

During sociocultural changes in different states, the educational paradigm is changing, therefore new pedagogical ideas and concepts are called upon to define a new public consciousness, a new type of culture, new principles of scientific thinking and practical activities in the educational space. The global process of transition from the industrial to the information society, as well as the socioeconomic changes that are taking place, require transformations in many spheres of state activity. This applies mainly to the education system. The national concept of educational development provides for the development of education on the basis of new progressive concepts, the introduction of new technologies and scientific and methodical achievements in the teaching and educational process, the creation of a new system of information support of education, the country's entry into the transcontinental computer information system.

The development of the educational system should lead to the emergence of new opportunities in the world educational space in relation to: updating the teaching content and methods of teaching disciplines and dissemination of knowledge; the expansion of access to all levels of education and realisation of the possibility of its receipt by a large number of young people; the implementation of a continuing education system; and individualisation in mass education.

The specificity of integration processes in education are defined by a number of principles. These are humanity, democracy, mobility, advancement, openness, continuity, phasing, structure, equality, and unity in diversity. The characteristics of the integration process in terms of information support are flexibility, modularity, parallelism, unlimited number of participants, profitability, technological effectiveness, social equality, internationality, teacher subjectivity and didactic security.

The content of integration processes is aimed at integrating educational systems. The maximum convergence of the countries of the world in all spheres by the principle of "Unity in diversity", presupposes a commonality of systems, while maintaining national lines of communication opens up the integrity of the integration processes. In the process of integration, the following conditions require to be met: state sovereignty; equality of state parties in integration processes; respect for human rights; respect for international obligations; consideration of the current state of education systems in each state and priority directions for their development; taking into account the historical experience of the development of education systems in the participating states, as well as international experience in this field; the inadmissibility of discrimination in education for any reasons, including nationality, gender, language, etc.; the identity of the interstate component of state standards; identity of qualification requirements for both core subjects and new specialties; the identity of state education policy in all countries; the identity of all education levels, 
durations of education at each level and types of educational institutions; the identity of forms of education; the identity of education certificates, the regulatory framework and the mechanism for establishing the equivalence and mutual recognition of state documents on education, academic degrees and ranks.

\section{Conclusion}

Interest in the problems of the integration processes, manifested by the world and European community in education, is due to the fact that in the conditions of intensive development of science and transition to the information society, increased attention to the trends driving the processes of unification of components of educational systems is required. The tendencies, characterising the development of integration processes in education are: growth in the scale of education; diversification of education in institutional forms, levels and content; cooperation of states in accordance with the convergence of government policies in the field of education; partnership at all levels of control, including in education; internationalisation of education; educational competition; unversatility, globalism, flexibility of education; access to education; distantance education; technologisation and computerisation of educational infrastructure; lifelong education; the creation of targeted supranational programmes; transformation of traditional systems and the like.

\section{REFERENCES}

Afanasiev V. (1973). About system approach in social research. Questions of philosophy, (6), 98-112.

Anohin P.K. (1980). Key problems of the theory of functional system. Moscow: Hayka.

Belogurov A. (2012). Strategy and methodology of sociocultural modernization of regional education. Pedagogics, (2), 13-22.

Bologna for Pedestrians. (19 June 1999). The Council of Europe Internet Portal. Retrieved April 28, 2010 from: https://www.coe.int/t/dg4/highereducation/EHEA2010/BolognaPedestrians_en.asp.

Concept of social development of the Union State. (2002). Minsk.

Dzhurinsky, A. (2014). Internalization of the higher education in the modern world. Pedagogics (3), 83-92.

The history of European cooperation in education and training. Europe in the making - an example. (2006). Luxembourg: Office for Official Publications of the European Communities

Federal law on higher and graduate professional education. August 22, 1996. N 125-Ф3

Higher Ed Inc (2018, August 14). The Economist. Retrieved from: https://www.economist.com/ special-report/2005/09/08/higher-ed-inc.

Higher Education Amendments of 1972, Public Law No. 92-318, 86 Stat. 235. 


\section{EASTERN EUROPEAN JOURNAL OF TRANSNATIONAL RELATIONS}

Law of Russian Federation on education. July 10, 1992. N 3266-1.

Liferov A. (2001). Regional aspects of reintegration of educational space of CIS countries. Moscow.

Liferov A. (2005). Education in strategy of multinational corporations. Pedagogics, (2), 79-90.

Onokoy L. (2004). Russia on the way of integration into the all-European education system: sociology and education. Sociological research, (2), 2004, 80-85.

The concept of continuous education in uniform educational space of the CIS countries (1998).

The SAGE Handbook of International Higher Education (2015). London. Sage.

Vulfson B. (2002). World educational space at a boundary of the XXI century. Pedagogics (10), 3-14.

World education report. To knowledge society. (2015). New York: UNESCO publishing. 